\title{
Effect of Dai-Saiko-To (Da-Chai-Hu-Tang) on LDL-Receptor Gene Expression in Human Hepatoma Cell Line (HepG2)
}

\author{
Akira Iizuka $^{1 *}$, Fumihiko Yoshie ${ }^{1}$, Sakae Amagaya ${ }^{2}$, Takaaki Yasuda ${ }^{3}$, Maki Iizuka ${ }^{4}$, \\ Haruyo Yamaguchi ${ }^{5}$, Seiji Nagumo ${ }^{5}$, Kazuo Kondo ${ }^{4}$ \\ ${ }^{1}$ Clinical Pharmacy Education Center for Integrative Medicine, Nihon Pharmaceutical University, Saitama, Japan; ${ }^{2}$ Department of \\ Kampo Pharmacological Sciences, Nihon Pharmaceutical University, Saitama, Japan; ${ }^{3}$ Department of Medicinal Chemistry, Nihon \\ Pharmaceutical University, Saitama, Japan; ${ }^{4}$ Institute of Environmental Science for Human Life, Ochanomizu University, Tokyo, \\ Japan; ${ }^{5}$ Department of Medicinal Plant Science, Hoshi University Ebara, Tokyo, Japan. \\ Email: *a.iizuka@nichiyaku.ac.jp
}

Received December $21^{\text {st }}, 2012$; revised January $23^{\text {rd }}, 2013$; accepted February $1^{\text {st }}, 2013$

\begin{abstract}
We previously reported that Dai-saiko-to (Da-Chai-Hu-Tang), a traditional Japanese kampo medicine, increased LDL receptor mRNA expression in the liver of the hypercholesterolemic rabbits. In this study, we focused on LDL receptor gene expression in a human hepatoma cell line (HepG2) treated with Dai-saiko-to extract and the extracts of eight herbs presented in Dai-saiko-to. Dai-saiko-to extract significantly increased LDL receptor gene and SREBP2 gene expression compared with the control. The extracts of four herbs, Bupleurum root, Pinellia tuber, Scutellaria root and Peony root significantly increased the LDL receptor gene expression. Whereas, Jujube, Immature orange, Ginger and Rhubarb extracts did not change the gene expression. These results suggest that Dai-saiko-to increased the expression of the cholesterol transport gene (LDL receptor) regulated by SREBP2 gene in the human hepatoma cell line. The pharmacological activity of Dai-saiko-to against hypercholesterolemia and atheromatous lesions related for these four herbal components.
\end{abstract}

Keywords: Kampo; Dai-Saiko-To; LDL Receptor; Gene Expression; HepG2

\section{Introduction}

It is well known that hypercholesterolemia is a major risk factor for coronary heart disease [1,2]. Several kinds of drugs are used to improve the plasma lipid levels of patients with hypercholesterolemia [3-6]. Some traditional Japanese kampo medicines are used clinically to treat hyperlipidemia, diabetes mellitus, and obesity in Japan [7]. Dai-saiko-to (Da-Chai-Hu-Tang) is used clinically to alleviate hypertension, cholestasis, and various causes of liver dysfunction. We previously reported that Dai-saikoto inhibited the progression of atherosclerotic lesions in heritable hyperlipidemic model rabbits (KHC rabbits) [8-10]. In addition, plasma lipid levels were decreased and low density lipoprotein (LDL) receptor mRNA expression in the liver was increased in the Dai-saiko-to treated KHC rabbits. In the present study, we demonstrated that the antiatherosclerotic effects of Dai-saiko-to arise from many factors, including antioxidation and relation to gene expression. Our results demonstrate that Dai-saiko-to provides a combination of beneficial thera-

${ }^{*}$ Corresponding author. peutic effects against atherosclerosis. Dai-saiko-to inhibited the development of atheromatous plaques and decreased both LDL cholesterol and plasma cholesterol levels. Moreover, Dai-saiko-to showed antioxidative activity both in vivo and in vitro. Therefore, this medicine is beneficial for the treatment of hypercholesterolemia and atheromatous lesions. Unfortunately, the antiatherosclerotic effect of each component of Dai-saiko-to is not understood and further study is needed to elucidate the mechanism of action. The aim of the present study was to determine the effects of Dai-saiko-to on LDL receptor gene expression in a human hepatoma Cell line (HepG2) to clarify the pharmacological mechanism of Dai-saiko-to.

\section{Methods}

\subsection{Dai-Saiko-To Extract}

Dai-saiko-to manufactured by Tsumura \& Co. is a dried decoction of a mixture of eight medicinal herbs (Lot. No. 2040008010). Six grams of Bupleurum root (Bupleurum falcatum L.), $4 \mathrm{~g}$ of Pinellia tuber (Pinellia ternata Breit), $3 \mathrm{~g}$ of Scutellaria root (Scutellaria baicalensis Georgi), 3 
$\mathrm{g}$ of Peony root (Paeonia lactiflora Pallas), $3 \mathrm{~g}$ of Jujube (Zizyphus jujuba Mill. var. inermis Rehder), $2 \mathrm{~g}$ of Immature Orange (Citrus aurantium L. var. daidai Makino), $1 \mathrm{~g}$ of Ginger (Zingiber officinale Roscoe) and $1 \mathrm{~g}$ of Rhubarb (Rheum palmatum L.) were each added to 700 $\mathrm{mL}$ of water and the mixture was boiled for 1 hour. Then, the mixture was filtered and concentrated to $300 \mathrm{~mL}$. This decoction was spray-dried to yield $4.5 \mathrm{~g}$ of powdered extract, which represented the daily clinical dose. The quality of each crude drug was tested in accordance with the Japanese pharmacopoeia. Moreover, the test sample was analyzed by three-dimensional HPLC and the ingredients were checked.

\subsection{Preparation of Extracts of Herbal Drugs}

Each eight herbal drugs was ground and added to twenty times of water and boiled until the volume was reduced to half the original volume. Each decoction was filtered through gauze while hot and evaporated under reduced pressure at 40 degrees to give extract.

\subsection{Cell Culture}

The human hepatoma cell line HepG2 was purchased from the American Type Culture Collection (Rockville, MD, USA). HepG2 cells were grown in monolayer cultures to confluency in $75 \mathrm{~cm}^{2}$ flasks containing $15 \mathrm{~mL}$ of Eagle's minimal essential medium (MEM) supplemented, with $10 \%(\mathrm{v} / \mathrm{v}) \mathrm{FBS}$, penicillin (100 units $/ \mathrm{mL})$, streptomycin $(100 \mathrm{ug} / \mathrm{mL})$, and glutamine $(4 \mathrm{mM})$. HepG2 cells were maintained in an incubator at 37 degrees centigrade in 5\% $\mathrm{CO}_{2}$. Cells were seeded into six-well plates at $8 \times 10^{5}$ cells/ well and maintained for 4 days until examination.

Dai-saiko-to extract $(0.5$ and $1 \mathrm{mg} / \mathrm{mL})$ or Bupleurum root $(0.26 \mathrm{mg} / \mathrm{mL})$, Pinellia tuber $(0.17 \mathrm{mg} / \mathrm{mL})$, Scutellaria root $(0.13 \mathrm{mg} / \mathrm{mL})$, Peony root $(0.13 \mathrm{mg} / \mathrm{mL})$, Jujube $(0.13 \mathrm{mg} / \mathrm{mL})$, Immature Orange $(0.09 \mathrm{mg} / \mathrm{mL})$, Ginger $(0.04 \mathrm{mg} / \mathrm{mL})$ and Rhubarb $(0.04 \mathrm{mg} / \mathrm{mL})$ extracts were added to HepG2 cell line and incubation was carried out for 8 hours.

\subsection{Detection of LDL mRNA Levels in Human Liver Cell Line}

Total RNA was extracted from the cells using a Qiagen Rneasy Mini Kit (Qiagen GmbH, Hilden, Germany) according to the manufacturer's protocol and then stored at -80 degrees centigrade until use.

cDNA was synthesized from 1 microgram of RNA using a SuperArray cDNA synthesis kit (SuperArray Bioscience Co. Frederick, MD, USA). The following primers were used: for LDL receptor, F, 5'-CCC CGC AGA TCA AAC CCC CAC TC and R, 5'-AGA CCC CCA GGC AAA GGA AGA CGA. For GAPDH, F, 5'-CCT CCC
GCT TCG CTC TCT and R, 5'-GCT GGC GAC GCA AAA GA were used as internal controls. For SREBP2, F, 5'-CGC CAC CTG CCC CTC TCC TTC C TC and R, 5'-A TGC CCT GCC ACC TAT CCT CTC ACG.

PCR using these primes were performed with an initial cycle of 5 min at 95 degrees centigrade followed by 30 cycles of 95 degrees centigrade for $15 \mathrm{~min}, 95$ degrees centigrade for $15 \mathrm{sec}, 55$ degrees centigrade for $30 \mathrm{sec}$ and 72 degrees centigrade for $30 \mathrm{sec}$. After electrophoresis by ethidium bromide staining, the amount of PCR products was analyzed with a Molecular Imager FX Pro system (BIO-RAD) and represents the expression ratio of mRNA to glyceraldehyde 3-phosphate dehydrogenase (GAPDH).

\subsection{Statistical Evaluation}

Results are expressed as means \pm S.E. Differences between groups were analyzed by ANOVA with the Dunnett's test for post hoc analysis. Differences were considered significant at $\mathrm{P}<0.05$.

\section{Results}

\subsection{Three-Dimensional HPLC Profile of Dai-Saiko-To}

A three-dimensional HPLC profile of the methanol solution of Dai-saiko-to is shown in Figure 1. The UV-absorption-based analysis clearly showed the presence of the following constituents in the Dai-saiko-to powder: saikosaponins b1 and b2 (originating from Bupleurum root); wogonin, wogonin 7-O-glucuronoside, baicalin, baicalein 7-O-glucoside and skullcapflavone II (from Scutellaria root); paeoniflorin, albiflorin and benzoylpaeoniflorin (from Peony root); naringin, naringenin, narirutin, hesperidin and neohesperidin (from Immature Orange); rhein, rhein 8-O-glucoside, and chrysophanols 1-O-glucoside and 8-O-glucoside (from Rhubarb).

\subsection{Yields of Extract of Eight Herbal Drugs}

The yields of each extract were presented in Table 1. Each yield from each herbal drug was from $4.2 \%$ to $60 \%$, respectively.

\subsection{LDL Receptor mRNA Expression in HepG2 Cells}

The expression ratios of LDL receptor and SREBP-2 mRNA to GAPDH in HepG2 cells are presented in Figures 2 and 3. LDL receptor and SREBP-2 mRNA expression levels were significantly increased by Daisaiko-to. Moreover the mixture of eight herb extracts also expressed the LDL receptor mRNA. Table 2 shows that the four herbal extracts such as Bupleurum root, Pinellia 


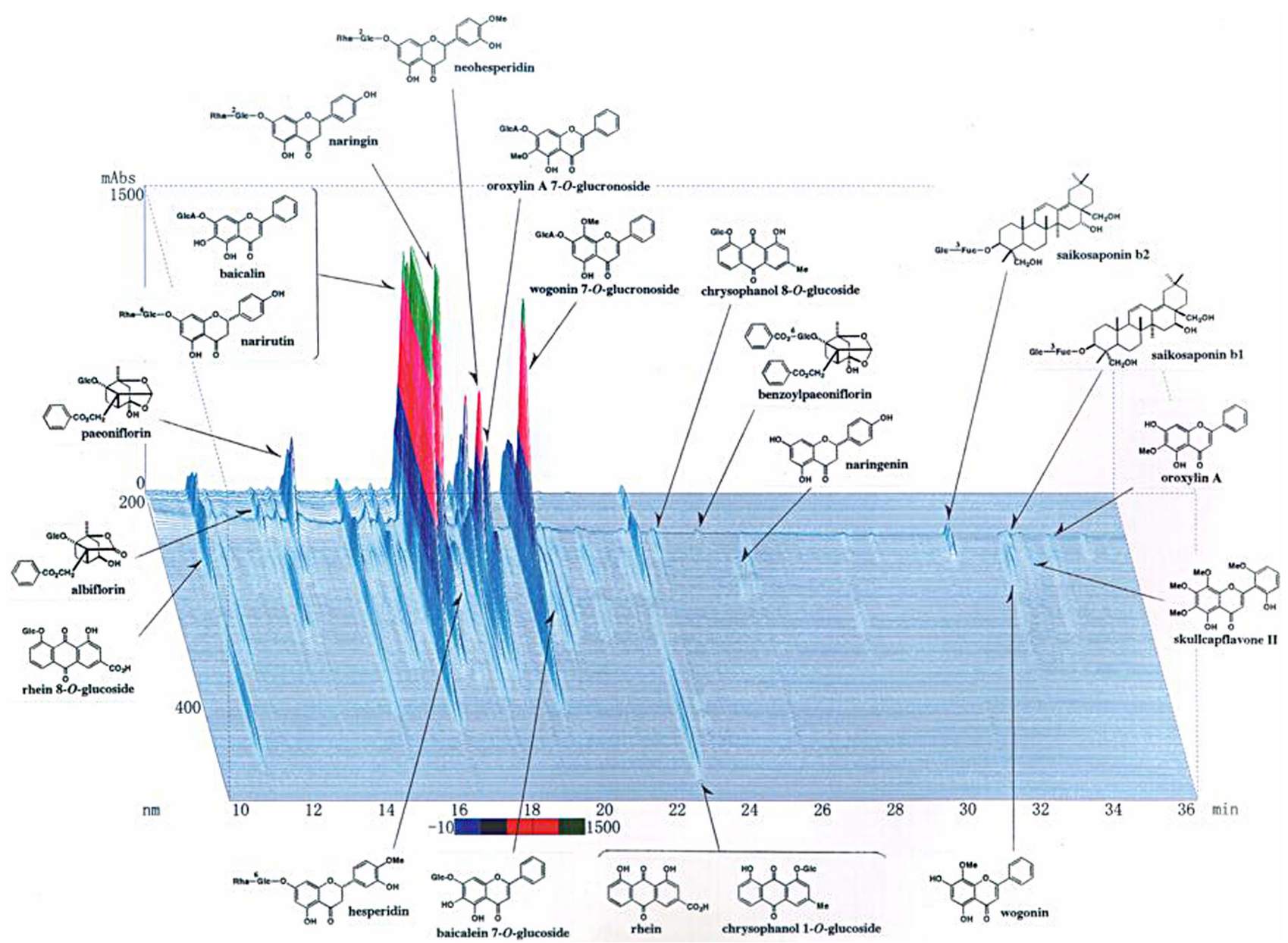

Figure 1. Three-dimensional HPLC profile of the methanol solution of Dai-saiko-to. The analysis based on UV-absorption clearly showed the presence of the following constituents in the Dai-saiko-to powder.

Table 1. The yields of extract of eight herbal drugs.

\begin{tabular}{cc}
\hline Herbal Drugs & Yields \\
\hline Bupleurum Root & $8.2 \%$ \\
Pinellia Tuber & $4.7 \%$ \\
Scutellaria Root & $19.8 \%$ \\
Peony Root & $23.3 \%$ \\
Jujube & $60.7 \%$ \\
Immature Orange & $42.0 \%$ \\
Ginger & $15.7 \%$ \\
Rhubarb & $28.8 \%$ \\
\hline
\end{tabular}

tuber, Scutellaria root and Peony root were significantly increased the LDL receptor mRNA expression levels. In contrast, the other four herbal extracts did not change the mRNA expression levels compared with the control.

\section{Discussion}

Lifestyle-related disease such as dyslipidemia, are one of the most important risk factors for coronary artery disease and atherosclerosis. Previous trials have shown that

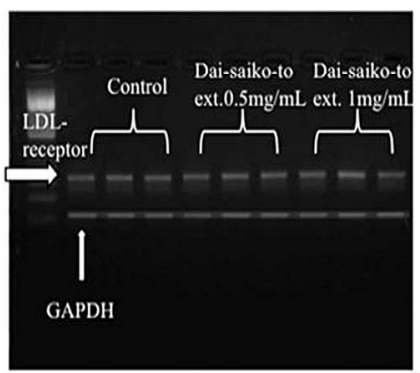

(a)

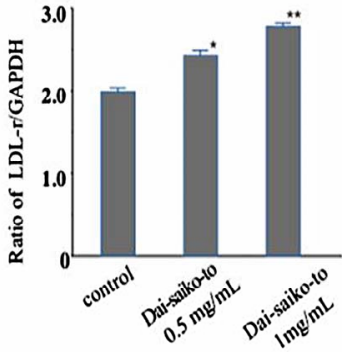

(b)
Figure 2. Effect of Dai-saiko-to on the expression of LDLreceptor mRNA in HepG2 cells. Representative data of LDL receptor mRNA RT-PCR productsin HepG2 cells. Effect of Dai-saiko-to on the expression of LDL receptor mRNA quantified relative to GAPDH in the HepG2 cells shows RT-PCR products. Vertcal bars indicated the mean \pm S.E. $(\mathrm{n}=3)$. ${ }^{*} \mathbf{P}<0.05$ and ${ }^{* *} \mathbf{P}<0.01$, significantly different from the control.

3-hydroxy-3-methylglutaryl coenzyme A (HMG CoA) reductase inhibitors, such as statins, decreased plasma lipid levels and inhibited coronary artery disease $[11,12]$. 


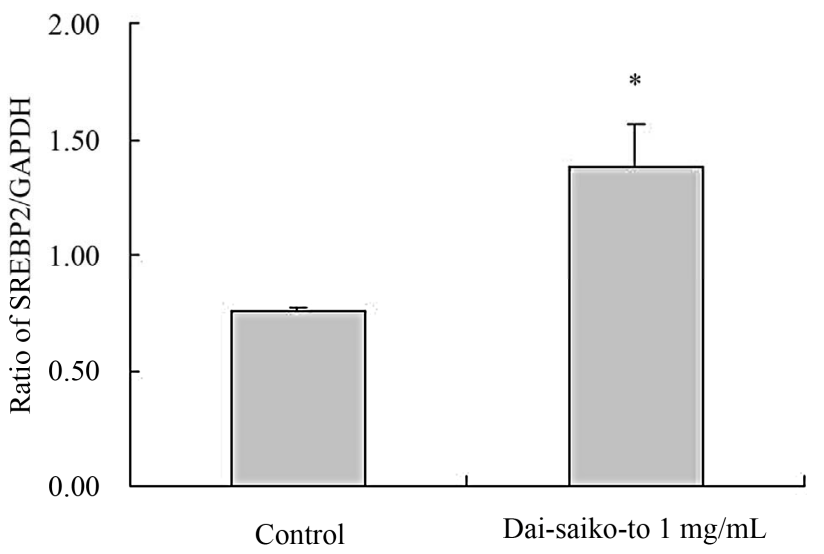

Figure 3. Effect of Dai-saiko-to on the gene expression of SREBP-2 mRNA in HepG2 cells. The data represented the SREBP-2 mRNA gene quantified relative to GAPDH.

Table 2. LDL receptor mRNA expression rate of herbal drugs in HepG2 cell.

\begin{tabular}{cc}
\hline Herbal Drugs & LDL-Receptor/GAPDH Ratio \\
\hline Control & $3.43 \pm 0.20$ \\
Bupleurum Root & $4.50 \pm 0.41^{*}$ \\
Pinellia Tuber & $4.29 \pm 0.16^{*}$ \\
Scutellaria Root & $4.55 \pm 0.27^{*}$ \\
Peony Root & $5.30 \pm 0.66^{* * *}$ \\
Jujube & $2.40 \pm 0.03^{*}$ \\
Immature Orange & $2.60 \pm 0.25$ \\
Ginger & $2.81 \pm 0.24$ \\
Rhubarb & $2.37 \pm 0.17^{*}$ \\
Mixture of the Above the Eight Herbs & $4.20 \pm 0.51^{*}$ \\
\hline
\end{tabular}

Each value represents the mean \pm S.E. ${ }^{*} \mathrm{P}<0.05,{ }^{* * *} \mathrm{P}<0.001$, significantly different from the control.

A number of hypocholesterolemic drugs are used to improve plasma lipid levels of patients. Low-density lipoprotein cholesterol lowering drugs suppressed the LDL receptor gene expression in the liver, thereby reducing cardiovascular disease risk and plaque progression in the artery [13-15].

To our knowledge, this is the first study to demonstrate the molecular mechanism of inducible regulation of Dai-saiko-to extraction in human liver cells. The LDL receptor, a transmembrane glycoprotein, is one of the most important regulators of plasma LDL cholesterol levels. LDL is the major cholesterol-carrying lipoprotein in plasma. The receptor protein binds LDL and transports it into cells via endocytosis. The phenotypes of HepG2 cells are similar to those of human hepatocytes and commonly used to screen for lipid-regulating drugs [1618]. To evaluate the molecular basis of the hypocholesterolemic effect of Dai-saiko-to, we selected HepG2 cells as a model to study the regulation of LDL receptor expression.
We previously reported the pharmacological effects of Dai-saiko-to on the expression of apolipoprotein (apo)-B, apo-E, and LDL receptor mRNA in the liver of KHC rabbits, but did not clarify the effects on major human organs, specifically the liver [19]. Therefore, we focused on LDL receptor gene expression in the human hepatoma Cell line treated with Dai-saiko-to. Dai-saiko-to contains eight herbs. The purpose of this study was to determine whether or not. Dai-saiko-to increased LDL receptor mRNA expression, which direct stimulated effect and/or direct for gene expression signal in the HepG2 cells.

Yamamoto et al. reported that one of the pharmacological mechanism of Dai-saiko-to is the reduction of cholesterol synthesis. Reduced VLDL synthesis and excretion were noted in a HepG2 cell line cultured with Dai-saiko-to [20]. In our present study, both Dai-saiko-to and the mixture of eight herbal extracts significantly increased LDL-receptor mRNA expression in HepG2 cells. Moreover, four herbal extracts, namely, Bupleurum root, Pinellia tuber, Scutellaria root, and Peony root, also increased LDL receptor mRNA expression.

These four herbs contain flavonoids and flavonoidsrich compounds that have frequently been reported to inhibit the modification of LDL [21,22]. Catechins in green tea increased the LDL receptor mRNA expression as well [23]. Gylling et al. reported that plant sterols regulated cholesterol metabolism [24]. To increase hepatic LDL receptor mRNA expression, SREBPs should bind to the LDL receptor gene. When cellular cholesterol levels fall SREBPs, which exist in the inactive form in the cytoplasma are cleaved by proteases and activated as transcription factors [25]. Then, the activated SREBPs migrate to the nucleus where they bind to the LDL receptor gene to stimulate LDL receptor protein production, thereby allowing more cholesterol to enter the cell. Therefore, we hypothesize that flavonoids and flavonoid-like constructs stimulate LDL receptor mRNA expression and/or up-regulate sites which act SREBPs in HepG2 cells. On the other hand, $\beta$-sitosterol is present in large amounts in Scutellaria root. Beta-sitosterol is a steroid-like structure and cholesterol and steroid structural components stimulate sterol regulatory element binding protein-2 (SREBP-2) [26].

Although the main active compounds are unclear and LDL receptor mRNA expression effects didn't reveal the details of the synergistic mechanism of crude drugs.

A single oral administration of Scutellaria root decreased serum and hepatic lipid levels in hyperlipidemic rats [27]. We suspect that those effects may play an important role in the inhibition of the progression of atherosclerotic lesions. To inhibit the progression of atherosclerosis and atherosclerotic lesions, not only antioxidative effects but also other protective effects on blood, cells, artery wall, lipids and other structures, may be at 
work. In addition, LDL receptor mRNA gene expression in the liver cells may protect against hypercholesterolemia and atheromatous lesions.

Together the results show that the effect of Dai-saikoto on LDL receptor mRNA expression in HepG2 cells is at least related to those of the four herbs. Further studies are needed to elucidate the mechanism of the antiatherosclerotic effect of Dai-saiko-to.

\section{Acknowledgements}

This study was financially supported by a Grant-in-Aid from the Takeda Science Foundation.

\section{REFERENCES}

[1] Multiple Risk Factor Intervention Trial Research Group, "Multiple Risk Factor Intervention Trial. Risk Factor Changes and Mortality Results," JAMA, Vol. 248, No. 12, 1989, pp. 1465-1477.

[2] M. A. Denke, "Review of Human Studies Evaluating Individual Dietary Responsiveness in Patients with Hypercholesterolemia," The American Journal of Clinical Nutrition, Vol. 62, No. 2, 1995, pp. 471S-477S.

[3] Lipid Research Clinics Program, "The Lipid Research Clinics Coronary Primary Prevention Trial Results: II. The Relationship of Reduction in Incidence of Coronary Heart Disease to Cholesterol Lowering," JAMA, Vol. 251, No. 3, 1984, pp. 365-374. doi:10.1001/jama.1984.03340270043026

[4] M. H. Frick, O. Elo, H. Kauko, O. P. Heinonen, P. Heinsalmi, P. Helo, J. K. Huttunen, P. Kaitaniemi, P. Koskinen, V. Manninen, H. Mäenpää, M. Mälkönen, M. Mänttäri, S. Norola, A. Pasternack, J. Pikkarainen, M. Romo, T. A. Sjöblom and E. A. Nikkilä, "Helsinki Heart Study: Primary-Prevention Trial with Gemfibrozil in MiddleAged Men with Dyslipidemia," The New England Journal of Medicine, Vol. 317, No. 20, 1987, pp. 1237-1245. doi:10.1056/NEJM198711123172001

[5] C. M. Ballantyne, J. Houri, A. Notarbartolo, L. Melani, L. J. Lipka, R. Suresh, S. Sun, A. P. Le Beaut, P. T. Sager and E. P. Veltri (for the Ezetimibe Study Group), "Effect of Ezetimibe Coadministered with Atorvastatin in 628 Patients with Primary Hypercholesterolemia. A Prospective, Randomized, Double-Blind Trial," Circulation, Vol. 107, 2003, pp. 2409-2415. doi:10.1161/01.CIR.0000068312.21969.C8

[6] M. Yokoyama, H. Origasa, M. Matsuzaki, Y. Matsuzawa, Y. Saito, Y. Ishikawa, S. Oikawa, J. Sasaki, H. Hishida, H. Itakura, T. Kita, A. Kitabatake, N. Nakaya, T. Sakata, K. Shimada and K. Shirato (for the Japan EPA Lipid Intervention Study (JELIS) Investigators), "Effects of Eicosapentaenoic Acid on Major Coronary Events in Hypercholesterolaemic Patients (JELIS): A Randomised OpenLabel, Blinded Endpoint Analysis," Lancet, Vol. 369, No. 9567, 2007, pp. 1090-1098. doi:10.1016/S0140-6736(07)60527-3

[7] S. Yamano, F. Sawai, T. Kagoshima and K. Dohi, "Effects of Dai-Saiko-To on Lipid Metabolism and Common
Carotid Hemodynamics in Patients with Hyperlipidemia," Medical and Pharmaceutical Society for WAKAN-YAKU, Vol. 11, 1994, pp. 38-43.

[8] A. Iizuka, T. O. Iijima, F. Yoshie, B. Makino, S. Amagaya, Y. Komatsu, K. Kondo, A. Matsumoto and H. Itakura, "Inhibitory Effects of Dai-Saiko-To on the Progression of Atherosclerotic Lesions in Kurosawa and $\mathrm{Ku}-$ sanagi-Hypercholesterolemic Rabbits," Journal of Ethnopharmacology, Vol. 63, No. 3, 1998, pp. 209-218. doi:10.1016/S0378-8741(98)00083-X

[9] F. Yoshie, A. Iizuka, K. Kondo, A. Matsumoto, H. Itakura and Y. Komatsu, "Antiatherosclerotic Effect of DaiSaiko-To in Kurosawa and Kusanagi Hypercholesterolemic Rabbits," Research Communications in Pharmacology and Toxicology, Vol. 5, 2000, pp. 77-89.

[10] F. Yoshie, A. Iizuka, Y. Komatsu, A. Matsumoto, H. Itakura and K. Kondo, "Antiatherosclerotic Effect of DaiSaiko-To in Kurosawa and Kusanagi Hypercholesterolemic Rabbits," Pharmacological Research, Vol. 50, No. 1-2, 2004, pp. 223-230. doi:10.1016/j.phrs.2004.02.003

[11] K. Mizuno, N. Nakaya, Y. Ohashi, N. Tajima, T. Kushiro, T. Teramoto, S. Uchiyama and H. Nakamura (for the MEGA Study Group), "Usefulness of Pravastatin in Primary Prevention of Cardiovascular Events in Women: Analysis of the Management of Elevated Cholesterol in the Primary Prevention Group of Adult Japanese (MEGA study)," Circulation, Vol. 117, No. 4, 2008, pp. 494-502. doi:10.1161/CIRCULATIONAHA.106.671826

[12] J. Shepherd, S. M. Cobbe, I. Ford, C. G. Ishes, A. R. Lorimer, P. W. MacFarlane, J. H. McKillop and C. J. Packard, "Prevention of Coronary Heart Disease with Pravastatin in Men with Hypercholesterolemia," The New England Journal of Medicine, Vol. 333, No. 20, 1995, pp. 1301-1307. doi:10.1056/NEJM199511163332001

[13] T. Teramoto, T. Matsushita, Y. Horie and T. Watanabe, "Production of Apolipoprotein E-Rich LDL by the Liver. The Effect of Dietary Cholesterol and Some Lipid Lowering Agents," Annals of the New York Academy of Sciences, Vol. 598, 1990, pp. 301-307. doi:10.1111/j.1749-6632.1990.tb42301.x

[14] H. Nakamura, K. Arakawa, H. Itakura, A. Kitabatake, Y. Goto, T. Toyota, N. Nakaya, S. Nishimoto, M. Muranaka, A. Yamamoto, K. Mizuno and Y. Ohashi, "Primary Prevention of Cardiovascular Disease with Pravastatin in Japan (MEGA Study): A Prospective Randomized Controlled Trial," Lancet, Vol. 368, No. 9542, 2006, pp. 1155-1163. doi:10.1016/S0140-6736(06)69472-5

[15] R. G. Roberto, P. G. Robert, M. Satishkumar, A. M. Sabina, H. M. Carolyn, B. S. McCabe, P. C. Christopher and B. Eugene, "Baseline Low-Density Lipoprotein Cholesterol Is an Important Predictor of the Benefit of Intensive Lipid-Lowering Therapy. A PROVE IT-TIMI 22 (Pravastatin or Atorvastatin Evaluation and Infection TherapyThrombolysis in Myocardial Infection 22) Analysis," Journal of the American College of Cardiology, Vol. 52, No. 11, 2008, pp. 914-920.

[16] M. N. Salleh, I. Runnie, P. D. Roach, S. Mohamed and M. Y. Abeywardena, "Inhibition of Low-Density Lipoprotein Oxidation and Up-Regulation of Low-Density Lipoprotein Receptor in HepG2 Cells by Tropical Plant Extracts," 
Journal of Agricultural and Food Chemistry, Vol. 50, No. 13, 2002, pp. 3693-3697. doi:10.1021/jf011593f

[17] J. Liu, F. Zhang, C. Li, M. Lin and M. R. Briggs, "Synergistic Activation of Human LDL Receptor Expression by SCAP Ligand and Cytokine Oncostatin M," Arteriosclerosis, Thrombosis, and Vascular Biology, Vol. 23, No. 1, 2003, pp. 90-96. doi:10.1161/01.ATV.0000046229.77566.E5

[18] S. Yu-Poth, D. Yin, G. Zhao, P. M. Kris-Etherton and T. D. Etherton, "Conjugated Linoleic Acid Upregulates LDL Receptor Gene Expression in HepG2 Cells," Journal of Nutrition, Vol. 134, No. 1, 2004, pp. 68-71.

[19] A. Iizuka, F. Yoshie, Y. Komatsu, K. Kondo, A. Matsumoto and H. Itakura, "Effect of Dai-Saiko-To on Serum Lipid Levels and APOLIPOPROTEINB, and -E, and LDLReceptor Gene Expression in the Liver of Hypercholesterolemic Rabbits," Research Communications in Pharmacology and Toxicology, Vol. 6, 2001, pp. 205-214.

[20] K. Yamamoto, Y. Ogawa, T. Yanagita, F. Morita, N. Fukushima, I. Osaki, T. Mizuta, Y. Setoguchi and T. Sakai, "Pharmacological Effects of Dai-Saiko-To on Lipid Biosynthesis in Cultured Human Hepatocyte HepG2 Cells," Journal of Ethnopharmacology, Vol. 46, No. 1, 1995, pp. 49-54. doi:10.1016/0378-8741(95)01227-5

[21] M. G. L. Hertog, E. J. M. Feskens, P. C. H. Hollman, M. B. Katan and D. Kromhout, "Dietary Antioxidant Flavonoids and Risk of Coronary Heart Disease: The Zutphen Eldery Study," Lancet, Vol. 342, No. 8878, 1993, pp. 1007-1011. doi:10.1016/0140-6736(93)92876-U

[22] M. Viana, C. Barbas, B. Bonet, M. V. Bonet, M. Castro, M. V. Fraile and E. Herrera, "In Vitro Effects of a Flavonoid-Rich Extract on LDL Oxidation," Atherosclerosis,
Vol. 123, No. 1, 1996, pp. 83-91. doi:10.1016/0021-9150(95)05763-3

[23] C. Bursill, P. D. Roach, C. D. K. Bottema and S. Pal, "Green Tea Upregulates the Low-Density Lipoprotein Receptor through the Sterol-Regulated Element Binding Protein in HepG2 Liver Cell," Journal of Agricultural and Food Chemistry, Vol. 49, No. 11, 2001, pp. 5639-5645. doi:10.1021/jf010275d

[24] H. Gylling, M. Hallikainen, O. T. Raitakari, M. Laakso, E. Vartiainen, P. Salo, V. Korpelainen, J. Sundvall and T. A. Miettinen, "Long-Term Consumption of Plant Stanol and Sterol Esters, Vascular Function and Genetic Regulation," British Journal of Nutrition, Vol. 101, No. 11, 2009, pp. 1688-1695. doi:10.1017/S0007114508116300

[25] M. S. Brown and J. L. Goldstein, "The SREBP Pathway: Regulation of Cholesterol Metabolism by Proteolysis of a Membrane-Bound Transcription Factor," Cell, Vol. 89, No. 3, 1997, pp. 331-340. doi:10.1016/S0092-8674(00)80213-5

[26] S. V. Harding, T. C. Rideout and P. J. Jones, "Hepatic Nuclear Sterol Regulatory Binding Element Protein 2 Abundance Is Decreased and That of ABCG5 Increased in Male Hamsters Fed Plant Sterols," Journal of Nutrition, Vol. 140, No. 7, 2010, pp. 1249-1254. doi:10.3945/jn.109.120311

[27] Y. Kimura, M. Kubo, T. Tani, S. Arichi, H. Ohminami and H. Okuda, "Studies on Scutellariae Radix III. Effects on Lipid Metabolism in Serum, Liver and Fat Cells Of Rats," Chemical and Pharmaceutical Bulletin, Vol. 29, No. 8, 1981, pp. 2308-2312. doi: $10.1248 / \mathrm{cpb} .29 .2308$ 